\title{
General management of pulmonary arterial hypertension associated with adult congenital heart disease
}

\author{
Wendy Gin-Sing(D
}

\begin{abstract}
Over the past 15 years there have been significant improvements in the treatment of pulmonary arterial hypertension due to congenital heart disease. Patients now live for several decades, but morbidity and mortality remain high. This article describes the holistic management of this patient group with an emphasis on both the physical and psychosocial aspects of care, taking into account the consequences of chronic cyanosis, avoiding complications and improving quality of life.
\end{abstract}

Keywords: Pulmonary arterial hypertension, Congenital heart disease, Holistic care, Chronic cyanosis, Eisenmenger syndrome

\section{Background}

Improvements in the management and treatment of congenital heart disease (CHD) since the turn of the century have led to a population which is both growing and ageing [1]. An estimated $10-28 \%$ of these patients develop pulmonary arterial hypertension (PAH) $[2,3]$. As the age of the patients increase, so do co-morbidities and the long-term consequences of chronic cyanosis. It is, therefore, essential that this group of complex patients are managed in expert centres that are aware of the potential medical risk factors, can provide patient education, and improve quality of life [4] and life expectancy [5].

This article will discuss the general management of patients with PAH-CHD, with an emphasis on a holistic approach, taking into account not only the physical aspects of their care, but also the social and psychological needs of the patient and their family. The treatment of PAH-CHD with pulmonary vasodilator therapy is not

\footnotetext{
Correspondence: Wendy.gin-sing@nhs.net

Pulmonary Hypertension Service, Imperial College Healthcare NHS Trust, London, UK
}

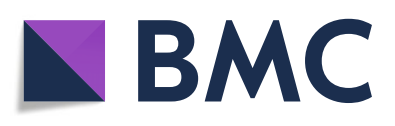

(c) The Author(s). 2020 Open Access This article is licensed under a Creative Commons Attribution 4.0 International License, which permits use, sharing, adaptation, distribution and reproduction in any medium or format, as long as you give appropriate credit to the original author(s) and the source, provide a link to the Creative Commons licence, and indicate if changes were made. The images or other third party material in this article are included in the article's Creative Commons licence, unless indicated otherwise in a credit line to the material. If material is not included in the article's Creative Commons licence and your intended use is not permitted by statutory regulation or exceeds the permitted use, you will need to obtain permission directly from the copyright holder. To view a copy of this licence, visit http://creativecommons.org/licenses/by/4.0/ The Creative Commons Public Domain Dedication waiver (http://creativecommons.org/publicdomain/zero/1.0/) applies to the data made available in this article, unless otherwise stated in a credit line to the data. covered as it is discussed in another paper in this supplement.

\section{Physical aspects of PAH-CHD care Management of the consequences of PAH-CHD (Table 1)} Chronic hypoxaemia is typical of Eisenmenger syndrome , the extreme end of the spectrum of PAH-CHD. I Hence, the use of supplemental oxygen not recommended for all ES patients, but should be nsidered in cases in which it produces a consistent in in arterial oxygen saturation and improvement in syptoms [4]. Indeed, in a small number of patients, term home oxygen therapy may improve sympmay also lead to dependence and physical deconditioning through immobilisation [7] and is, therefore, not recommended as routine care. Screening for sleep apnoea and nocturnal hypoventilation should be considered, especially in patients with Down Syndrome or spinal 
Table 1 Management of the consequences of PAH-CHD

\begin{tabular}{|c|c|c|}
\hline Problems & Causes & Solutions \\
\hline Chronic hypoxaemia & Right to left shunting through cardiac defects & $\begin{array}{l}\text { Consider supplemental oxygen only if results in an increase in arterial } \\
\text { oxygen saturation and improvement in symptoms } \\
\text { Screen for sleep apnoea and nocturnal hypoventilation }\end{array}$ \\
\hline $\begin{array}{l}\text { Hyperviscosity } \\
\text { syndrome }\end{array}$ & Erythrocytosis due to chronic hypoxaemia & $\begin{array}{l}\text { Maintain adequate hydration } \\
\text { Use therapeutic phlebotomy only in presence of moderate/severe } \\
\text { symptoms }\end{array}$ \\
\hline Haemoptysis & Bronchial collateral vessels & Consider bronchial artery embolization for large volume bleeds \\
\hline $\begin{array}{l}\text { Pulmonary artery } \\
\text { thrombosis/stroke }\end{array}$ & Sluggish pulmonary artery flow & Avoid iron deficiency and dehydration \\
\hline Gout/cholelithiasis & Hyperuricaemia due to erythrocytosis & $\begin{array}{l}\text { Maintain adequate hydration } \\
\text { Treat acute gout with colchicine, avoid non-steroidal anti-inflammatory } \\
\text { drugs } \\
\text { Allopurinol to maintain serum urate levels }<300 \mu \mathrm{mol} / \mathrm{L}\end{array}$ \\
\hline Chest pain & $\begin{array}{l}\text { Right ventricular ischaemia, coronary artery } \\
\text { compression, gastro-oesophageal reflux }\end{array}$ & Investigate cause and treat as appropriate \\
\hline Arrythmias & Related to heart defect $+/$ - intervention & Cardioversion, ablation, antiarrhythmic medication \\
\hline Hypothyroidism & Increased incidence with chronic cyanosis & $\begin{array}{l}\text { Annual thyroid function screening and treat as required } \\
\text { Care with iodine-based contrast media and amiodarone }\end{array}$ \\
\hline Renal dysfunction & Erythrocytosis and hypoxaemia & $\begin{array}{l}\text { Maintain adequate hydration } \\
\text { Care with nephrotoxic drugs and contrast agents }\end{array}$ \\
\hline
\end{tabular}

abnormality as this could contribute further to the level of hypoxaemia [8].

Chronic cyanosis results in elevated renal production of erythropoietin, which promotes erythropoiesis and secondary erythrocytosis. These higher levels of haemoglobin are beneficial as they enhance oxygen transport and delivery [4] to maintain tissue oxygenation and prevent hypoxic end-organ damage [9]. Repeated venesections can potentially increase the risk of ischaemic cerebrovascular events as this causes iron deficiency and microcytosis that may increase blood viscosity [10]. It is, therefore, recommended that therapeutic phlebotomy should only be performed in the presence of moderate/ severe hyperviscosity symptoms, which do not resolve with adequate hydration [9].

Patients with PAH-CHD develop robust bronchial collaterals with a consequent risk of arterial bleeding, resulting in haemoptysis [4]. Whilst this can be common in patients with ES physiology, and is a concern for patients and healthcare professionals, it does not seem to be predictive of mortality [11]. In patients with large volume haemoptysis, bronchial artery embolisation may be beneficial, even though evidence is lacking [12]. There is limited evidence to suggest that antifibrinolytics can help reduce the duration of bleeding [13].

A high incidence of pulmonary arterial (PA) thrombosis and strokes has been reported in ES [4, 14]. PA thrombosis is thought to be associated with ventricular dysfunction, and sluggish pulmonary artery blood flow, rather than solely coagulation abnormalities [14]. The incidence of stroke is also significantly higher in PAHCHD patients compared to the general population, especially at a younger age [15]. Despite the increased risk of embolic events, there are no data to support anticoagulation or antiplatelet treatment in ES, unless additional indications exist in the absence of significant haemoptysis, such as PA thrombosis, arrhythmia, embolic events, severe congestive heart failure [4].

Hyperuricaemia, is more common in ES, with serum levels of uric acid related directly to the degree of erythrocytosis [16]. When the elevation of the blood uric acid persists over a long period of time, it can result in precipitation and deposition of urate crystals in the joints and surrounding tissues. The incidence of gout increases with time and is more frequent in patients with co-existing renal disease. Patients should be encouraged to remain adequately hydrated and reduce the intake of purines in their diet. Non-steroidal anti-inflammatory drugs, which can cause sodium and fluid retention and may precipitate heart failure and renal dysfunction in ES patients, should be avoided. In acute attacks, the prompt use of colchicine is recommended although patients should be warned that this is likely to cause diarrhoea. Once the acute phase has resolved, allopurinol can be used to reduce the risk of recurrent gout [17]. The dose of allopurinol should be increased to achieve a serum urate level of $<300 \mu \mathrm{mol} / \mathrm{L}$. [18].

Cholelithiasis and asymptomatic gallstones are also more prevalent in the ES population, occurring in more than one third of patients with chronic cyanosis [19]. General or regional anaesthesia and sedation carry significant risks in these patients and essential surgery should be performed in tertiary centres with CHD and PAH expertise. 
Chest pain in patients with PAH-CHD may be related to a variety of causes, including right ventricular ischaemia, coronary artery compression due to enlarged pulmonary arteries and coronary artery disease. It is also important to consider gastro-oesophageal reflux as a potential cause for chest pain, as this is a common side effect of the phosphodiesterase 5 inhibitors used to treat PAH.

Arrhythmias may develop as a consequence of the underlying heart defect or as a sequela of interventions and are an important cause of morbidity and mortality in the PAH-CHD $[20,21]$ population. Compared to the general population atrial fibrillation occurs at a younger age in CHD patients and may be present in almost twothirds of these patients [22, 23], considerably increasing the risk of stroke and heart failure. Chronic oral anticoagulation should, therefore, be considered in adult congenital heart patients with a history of atrial fibrillation/ flutter [21]. Antiarrhythmic therapy with amiodarone can be effective in almost half of the patients but they require careful monitoring as systemic side effects and pro-arrhythmic effects are of concern [24]. Direct current cardioversion, with appropriate anticoagulation, should be considered in all PAH-CHD patients, especially those with advanced disease and high ventricular rates in whom haemodynamic instability can occur soon after the onset of arrhythmia $[25,26]$. Catheter ablation should be considered for patients with persistent or recurrent arrhythmias but this should be performed in centres that have experience in CHD electrophysiology procedures. It is always preferable, from a haemodynamic point of view, to obtain rhythm rather than rate control of atrial fibrillation and other arrhythmias in CHD [21].

Subclinical hypothyroidism is a common finding in cyanotic CHD and also appears to be associated with cyanosis and age [27]. As patients with CHD are three times more likely than the general population to develop mild hypothyroidism [28], regular thyroid evaluation is recommended, as this can develop into overt hypothyroidism. Individuals with Down syndrome are at an increased risk of developing thyroid disease, primarily autoimmune, with a lifetime prevalence ranging from 13 to $63 \%$ [29]. Patients with PAH-CHD who have been given iodine-based contrast media or are taking amiodarone require more frequent screening, as both an under and over-active thyroid can exacerbate symptoms and lead to heart failure.

Erythrocytosis and hypoxia can lead to early renal tubular injury [30]. Renal function is also affected by low cardiac output which is common in PAH-CHD patients and the incidence and severity of renal dysfunction increases with age. Mortality is 3-fold higher than normal in the 1 in 11 patients who have moderate or severe glomerular filtration rate reduction [31]. Care should be taken with nephrotoxic drugs and contrast agents. Patients should be advised to maintain adequate hydration at all times.

\section{Prevention of complications}

It is recommended that all patients are screened for metabolic syndrome as this is more common among adults with CHD than the general population [32], cyanotic patients however appear to be protected from coronary atherosclerosis [33]. Patients with PAH-CHD may be predisposed to obesity due to exercise limitation, and this is more pronounced in patients with Down syndrome [34]. A higher BMI was, however, associated with better prognosis in symptomatic CHD patients in one study, especially those with complex underlying cardiac defects, which suggests that cardiac cachexia may play a role in this population [35]. All patients with PAH-CHD should therefore be encouraged to maintain a healthy well-balanced diet and maintain a normal body weight.

Exercise capacity is reduced in PAH-CHD compared to normative standards and this significantly affects quality of life [36-38]. Mild to moderate activities seem to be beneficial [4] and patients should be encouraged to maintain fitness by remaining active within their own abilities, minimising the use of wheelchairs or other aids wherever possible [7]. Strenuous or extreme isometric efforts can be dangerous and should be discouraged [7] Results from formal exercise programmes have shown an improvement in $6 \mathrm{~min}$ walk distance, minimum haemoglobin oxygen saturation and functional class [39].

Infections can destabilise patients with PAH-CHD. Patients should, therefore, be encouraged to maintain good dental hygiene and have regular check-ups to avoid endocarditis, following local guidelines with regards to endocarditis prophylaxis. Unless there are specific contraindications, they should also receive annual influenza vaccinations and be vaccinated for chicken pox if appropriate. Pneumococcal vaccinations are essential as a recent large population study showed that pneumonia is the second leading cause of death in adults with CHD [40, 41].

PAH-CHD patients should be screened for iron deficiency and supplemental iron should be considered in patients with low ferritin or transferrin saturation plasma levels $[4,42]$.

Maternal death rates for patients with PAH remain high in the developed world [43]; in the PAH-CHD population the current risk of death is $28 \%$ [44] and is thus pregnancy is contraindicated [45]. Mandatory effective contraception is recommended [4]. Appropriate counselling and care, including psychological support, should therefore be part of the routine management of all women with PAH-CHD of reproductive age. Women 
who do become pregnant should be counselled and if they decide to continue their pregnancy, they should be optimally treated with PAH therapies (avoiding endothelin receptor antagonists due to increased teratogenic risk). There needs to be effective close collaboration between obstetricians and the PAH team [4] with a planned elective delivery and high dependency observation and care post-delivery for an extended period.

Non-cardiac surgery under general anaesthesia and even sedation should be avoided whenever possible [46, 47]. When essential, invasive procedures should be planned carefully and performed in centres with appropriate cardiac, pulmonary hypertension, anaesthetic and intensive care unit (ICU) expertise [7] and it is advisable that all PAH-CHD patients are monitored carefully for several hours or days after any invasive procedure in an intensive care setting [7]. In patients with right-to-left shunts, care should be taken to use air filters for all intravenous infusions to prevent air emboli.

Patients with PAH-CHD should receive lifestyle counselling. They should avoid smoking and excess alcohol, as this is associated with an increased risk of arrhythmias and heart failure [48], and they should be encouraged to maintain a well-balanced diet.

\section{Social and psychological}

The physical impact of PAH-CHD and especially ES, including cyanosis, finger clubbing and severely decreased exercise tolerance, can compromise social functioning [37]. Adults with CHD generally perceive themselves to have more poor health, exercise tolerance and quality of life than their peers without CHD [38]. It is, therefore, recommended that patients receive individualised consultations covering the type and intensity of physical activities which are safe, including those related to travel, hobbies, and sexual activities [7]. This is important as an improvement in exercise capacity and fitness has the scope of improving quality of life by enabling participation in social activities, while also aiding to combat obesity and its potential complications, such as sleep apnoea [7].

Patients with PAH-CHD may travel for holiday or work but care needs to be taken to ensure that they have comprehensive travel insurance and emergency access to adequate medical care. They should avoid destinations with extremes in temperature or altitude or where they need to walk for long periods in a hilly terrain. They should be advised not to take part in extreme sports and to avoid hot tubs and saunas. The majority of patients with ES do not require supplemental oxygen during commercial flights [13]. Traditional fitness-to-fly tests are difficult to interpret and do not seem to apply in cyanotic patients who are well adjusted to oxygen saturation fluctuations even with mild physical activities [7], as they have a blunted response to hypoxaemia.

Intimate relationships may be challenging for some adults with PAH-CHD due to lower body esteem, decreased sexual esteem and more distress during sex [49]. Sexual functioning can be impaired in adults with CHD, and there is a higher incidence of erectile dysfunction [50]. When problems are identified, sex and relationship counselling can be considered.

Patients with PAH-CHD are more likely to develop anxiety and depression [36], with a decreased quality of life and low self-esteem. The traditional belief that survival prospects in $\mathrm{PAH}-\mathrm{CHD}$ patients are far superior compared to other PAH aetiologies is not supported by recent studies [51, 52] and this leads to uncertainty about the future. It is important that psychological assessment is part of the routine care for the PAH-CHD population, and that issues are addressed by their specialist team or referral made for local support and management.

The PAH-CHD team can liaise with the employers of patients to ensure that, where possible, adjustments can be made to the work environment, such as designated parking spaces, offices on the ground floor or reduced hours to allow patients to continue to work and maintain an income. When this is not possible, it is essential that they are signposted to the health and income related benefits for which they (and their carers) may be eligible.

Patients should be referred to relevant patient associations ( $\mathrm{PH}$ and $\mathrm{ACHD}$ ), that not only provide excellent information, but also a social network and support groups for patients and their carers.

\section{Conclusions}

Over the past 15 years the development of PAH disease targeted therapies has led to improved symptom control and life expectancy for many patients with PAH-CHD. Patients now live for several decades, but due to the complexity of the disease with high morbidity and mortality levels they should be managed in expert centres delivering a holistic approach to ensure the best possible outcomes.

\section{Abbreviations \\ CHD: Congenital heart disease; ES: Eisenmenger Syndrome; ICU: Intensive care unit; PA: Pulmonary Arterial; PAH: Pulmonary arterial hypertension}

\section{Acknowledgements}

Not applicable.

\section{About this supplement}

This article has been published as part of Journal of Congenital Cardiology Volume 4 Supplement 12,020: Unmet needs in Pulmonary Hypertension associated with Adult Congenital Heart Disease (ACHD-PH). The full contents of the supplement are available at https://jcongenitalcardiology. biomedcentral.com/articles/supplements/volume-4-supplement-1. 


\section{Author's contributions}

The author has read and approved the final manuscript.

\section{Funding}

Publication costs are funded by a Medical and Educational Goods and Services (MEGS) grant and Actelion Pharmaceuticals UK Limited (who had no influence on manuscript writing).

\section{Availability of data and materials}

Not applicable.

\section{Ethics approval and consent to participate}

Not applicable.

\section{Consent for publication}

Not applicable.

\section{Competing interests}

The author declares that they have no competing interests.

Received: 12 November 2020 Accepted: 12 November 2020

Published: 16 December 2020

\section{References}

1. Marelli AJ, lonescu-lttu R, Mackie AS, Guo L, Dendukuri N, Kaouache M. Lifetime prevalence of congenital heart disease in the general population from 2000 to 2010. Circulation. 2014;130(9):749-56.

2. Engelfriet $\mathrm{P}$, Boersma $\mathrm{E}$, Oechslin $\mathrm{E}$, Tijssen J, Gatzoulis MA, Thilen U, et al. The spectrum of adult congenital heart disease in Europe: morbidity and mortality in a 5 year follow-up period. The euro heart survey on adult congenital heart disease. Eur Heart J. 2005;26(21):2325-33.

3. Duffels MG, Engelfriet PM, Berger RM, van Loon RL, Hoendermis E, Vriend JW, et al. Pulmonary arterial hypertension in congenital heart disease: an epidemiologic perspective from a Dutch registry. Int J Cardiol. 2007; 120(1874-1754):198-204

4. Galiè N, Humbert M, Vachiery JL, Gibbs S, Lang I, Torbicki A, et al. 2015 ESC/ ERS guidelines for the diagnosis and treatment of pulmonary hypertension: the joint task force for the diagnosis and treatment of pulmonary hypertension of the European Society of Cardiology (ESC) and the European Respiratory Society (ERS): endorsed by: Association for European Paediatric and Congenital Cardiology (AEPC), International Society for Heart and Lung Transplantation (ISHLT). Eur Heart J. 2016;37(1):67-119.

5. Mylotte D, Pilote L, lonescu-Ittu R, Abrahamowicz M, Khairy P, Therrien J, et al. Specialized adult congenital heart disease care: the impact of policy on mortality. Circulation. 2014;129(18):1804-12.

6. Sandoval J, Aguirre JS, Pulido T, Martinez-Guerra ML, Santos E, Alvarado P, et al. Nocturnal oxygen therapy in patients with the Eisenmenger syndrome. Am J Resp Crit Care. 2001;164(9):1682-7.

7. Dimopoulos K, Wort SJ, Gatzoulis MA. Pulmonary hypertension related to congenital heart disease: a call for action. Eur Heart J. 2014;35(11):691-700

8. Earing M, Drake M, Sowinski J, Reinhardt E, Saleska T, Katzmark L, et al. Prevalence and risk factors of obstructive sleep apnoea in adults with congenital heart disease. J Am Coll Cardiol. 2018;71(11) Supplement.

9. Spence MS, Balaratnam MS, Gatzoulis MA. Clinical update: cyanotic adult congenital heart disease. Lancet. 2007;370:1530-2 1474-547X (Electronic).

10. Rose SS, Shah AA, Hoover DR, Saidi P. Cyanotic congenital heart disease (CCHD) with symptomatic erythrocytosis. J Gen Intern Med. 2007;22(12): 1775-7.

11. Diller GP, Gatzoulis MA. Pulmonary vascular disease in adults with congenital heart disease. Circulation. 2007:115:1039-50 1524-4539 (Electronic).

12. Cantu J, Wang D, Safdar Z. Clinical implications of haemoptysis in patients with pulmonary arterial hypertension. Int J Clin Pract Suppl. 2012;177:5-12.

13. Prutsky G, Domecq JP, Salazar CA, Accinelli R. Antifibrinolytic therapy to reduce haemoptysis from any cause. Cochrane Database Syst Rev. 2016;11: CD008711.

14. Broberg CS, Ujita M, Prasad S, Li W, Rubens M, Bax BE, et al. Pulmonary arterial thrombosis in eisenmenger syndrome is associated with biventricular dysfunction and decreased pulmonary flow velocity. J Am Coll Cardiol. 2007;50:634-42 1558-3597 (Electronic).
15. Lanz J, Brophy JM, Therrien J, Kaouache M, Guo L, Marelli AJ. Stroke in adults with congenital heart disease: incidence, cumulative risk, and predictors. Circulation. 2015;132(25):2385-94.

16. Somerville J. Gout in cyanotic congenital heart disease. Br Heart J. 1961; 23(1):31-4.

17. Spieker LE, Ruschitzka FT, Lüscher TF, Noll G. The management of hyperuricemia and gout in patients with heart failure. Eur J Heart Fail. 2002; 4(4):403-10.

18. Hui M, Carr A, Cameron S, Davenport G, Doherty M, Forrester H, et al. The British Society for Rheumatology guideline for the Management of Gout. Rheumatology (Oxford). 2017;56(7):1056-9.

19. Shiina Y, Toyoda T, Kawasoe Y, Tateno S, Shirai T, Matsuo K, et al. The prevalence and risk factors for cholelithiasis and asymptomatic gallstones in adults with congenital heart disease. Int J Cardiol. 2011;152(2):171-6.

20. Drakopoulou M, Nashat H, Kempny A, Alonso-Gonzalez R, Swan L, Wort SJ, et al. Arrhythmias in adult patients with congenital heart disease and pulmonary arterial hypertension. Heart. 2018;104(23):1963-9.

21. Hernández-Madrid A, Paul T, Abrams D, Aziz PF, Blom NA, Chen J, et al. Arrhythmias in congenital heart disease: a position paper of the European heart rhythm association (EHRA), Association for European Paediatric and Congenital Cardiology (AEPC), and the European Society of Cardiology (ESC) working group on grown-up congenital heart disease, endorsed by HRS PACES, APHRS, and SOLAECE. Europace. 2018;20(11):1719-53.

22. Teuwen CP, Ramdjan TTKK, Götte M, Brundel BJJM, Evertz R, Vriend JWJ, et al. Time course of atrial fibrillation in patients with congenital heart defects. Circ Arrhythm Electrophysiol. 2015;8(5):1065-72.

23. Kirchhof P, Benussi S, Kotecha D, Ahlsson A, Atar D, Casadei B, et al. 2016 ESC quidelines for the management of atrial fibrillation developed in collaboration with EACTS. Eur J Cardiothorac Surg. 2016;50(5):e1-e88.

24. Koyak Z, Kroon B, de Groot JR, Wagenaar LJ, van Dijk AP, Mulder BA, et al. Efficacy of antiarrhythmic drugs in adults with congenital heart disease and supraventricular tachycardias. Am J Cardiol. 2013;112(9):1461-7.

25. Ammash NM, Phillips SD, Hodge DO, Connolly HM, Grogan MA, Friedman PA, et al. Outcome of direct current cardioversion for atrial arrhythmias in adults with congenital heart disease. Int J Cardiol. 2012;154(3):270-4.

26. Price LC, Dimopoulos K, Marino P, Alonso-Gonzalez R, McCabe C, Kemnpy A et al. The CRASH report: emergency management dilemmas facing acute physicians in patients with pulmonary arterial hypertension. Thorax. 2017; 72(11):1035-45.

27. Bak P, Hjortshøj CS, Gaede P, Idorn L, Søndergaard L, Jensen AS. Subclinical hypothyroidism: a common finding in adult patients with cyanotic congenital heart disease. Congenit Heart Dis. 2018;13(2):263-70.

28. Passeri E, Frigerio M, de Filippis $T$, Valaperta $R$, Capelli $P$, Costa $E$, et al. Increased risk for non-autoimmune hypothyroidism in young patients with congenital heart defects. J Clin Endocrinol Metab. 2011:96(7):E1115-9.

29. Hardy O, Worley G, Lee MM, Chaing S, Mackey J, Crissman B, et al. Hypothyroidism in Down syndrome: screening guidelines and testing methodology. Am J Med Genet A. 2004;124A(4):436-7.

30. Dittrich S, Haas NA, Bührer C, Müller C, Dähnert I, Lange PE. Renal impairment in patients with long-standing cyanotic congenital heart disease. Acta Paediatr. 1998:87(9):949-54.

31. Dimopoulos K, Diller G-P, Koltsida E, Pijuan-Domenech A, Papadopoulou SA, Babu-Narayan SV, et al. Prevalence, predictors, and prognostic value of renal dysfunction in adults with congenital heart disease. Circulation. 2008; 117(18):2320-8.

32. Deen JF, Krieger EV, Slee AE, Arslan A, Arterburn D, Stout KK, et al. Metabolic Syndrome in Adults With Congenital Heart Disease. J Am Heart Assoc. 2016;5(2): e001132.

33. Perloff JK. Cyanotic congenital heart disease the coronary arterial circulation Curr Cardiol Rev. 2012:8(1):1-5.

34. Lerman JB, Parness IA, Shenoy RU. Body weights in adults with congenital heart disease and the obesity frequency. Am J Cardiol. 2017;119(4):638-42.

35. Brida M, Dimopoulos K, Kempny A, Liodakis E, Alonso-Gonzalez R, Swan $L$, et al. Body mass index in adult congenital heart disease. Heart. 2017; 103(16):1250-7

36. Diller GP, Dimopoulos K, Okonko D, Li W, Babu-Narayan SV, Broberg CS, et al. Exercise intolerance in adult congenital heart disease: comparative severity, correlates, and prognostic implication. Circulation. 2005;112(6): 828-35.

37. Dimopoulos K, Okonko DO, Diller G-P, Broberg CS, Salukhe TV, BabuNarayan SV, et al. Abnormal ventilatory response to exercise in adults with 
congenital heart disease relates to cyanosis and predicts survival. Circulation. 2006;113(24):2796-802.

38. Bruto VC, Harrison DA, Fedak PWM, Rockert W, Siu SC. Determinants of health-related quality of life in adults with congenital heart disease. Congenit Heart Dis. 2007;2(5):301-13.

39. Martínez-Quintana E, Miranda-Calderín G, Ugarte-Lopetegui A, RodríguezGonzález F. Rehabilitation program in adult congenital heart disease patients with pulmonary hypertension. Congenit Heart Dis. 2010;5(1):44-50.

40. Diller G-P, Kempny A, Alonso-Gonzalez R, Swan L, Uebing A, Li W, et al. Survival prospects and circumstances of death in contemporary adult congenital heart disease patients under follow-up at a large tertiary Centre. Circulation. 2015;132(22):2118-25.

41. Raissadati A, Nieminen H, Haukka J, Sairanen H, Jokinen E. Late causes of death after pediatric cardiac surgery: a 60-year population-based study. J Am Coll Cardiol. 2016;68(5):487-98.

42. Tay ELW, Peset A, Papaphylactou M, Inuzuka R, Alonso-Gonzalez R, Giannakoulas $G$, et al. Replacement therapy for iron deficiency improves exercise capacity and quality of life in patients with cyanotic congenital heart disease and/or the Eisenmenger syndrome. Int J Cardiol. 2011;151(3): 307-12.

43. Kiely DG, Condliffe R, Wilson VJ, Gandhi SV, Elliot CA. Pregnancy and pulmonary hypertension: a practical approach to management. Obstet Med. 2013;6(4):144-54

44. Bedard E, Dimopoulos K, Gatzoulis MA. Has there been any progress made on pregnancy outcomes among women with pulmonary arterial hypertension? Eur Heart J. 2009:30:256-65.

45. Regitz-Zagrosek V, Blomstrom Lundqvist C, Borghi C, Cifkova R, Ferreira R, Foidart JM, et al. ESC guidelines on the management of cardiovascular diseases during pregnancy: the task force on the Management of Cardiovascular Diseases during pregnancy of the European Society of Cardiology (ESC). Eur Heart J. 2011;32(24):3147-97.

46. Lovell AT. Anaesthetic implications of grown-up congenital heart disease. $\mathrm{Br}$ J Anaesth. 2004:93:129-39 0007-0912 (Print).

47. Price LC, Montani D, Jaïs X, Dick JR, Simonneau G, Sitbon O, et al. Noncardiothoracic nonobstetric surgery in mild-to-moderate pulmonary hypertension. Eur Respir J. 2010;35(6):1294-302.

48. Piano MR. Alcohol's effects on the cardiovascular system. Alcohol Res. 2017; 38(2):219-41.

49. Winter MM, Reisma C, Kedde H, Bouma BJ, Vis JC, Luijendijk P, et al. Sexuality in adult patients with congenital heart disease and their partners. Am J Cardiol. 2010;106(8):1163-8 1168.e1-8.

50. Opić P, Roos-Hesselink JW, Cuypers JAAC, Witsenburg M, van den Bosch A, van Domburg RT, et al. Sexual functioning is impaired in adults with congenital heart disease. Int J Cardiol. 2013;168(4):3872-7.

51. Diller GP, Dimopoulos K, Broberg CS, Kaya MG, Naghotra US, Uebing A, et al. Presentation, survival prospects, and predictors of death in Eisenmenger syndrome: a combined retrospective and case-control study. Eur Heart J. 2006;27(14):1737-42.

52. Barst RJ, IVy DD, Foreman AJ, McGoon MD, Rosenzweig EB. Four- and seven-year outcomes of patients with congenital heart disease-associated pulmonary arterial hypertension (from the REVEAL registry). Am J Cardiol. 2014;113(1):147-55.

\section{Publisher's Note}

Springer Nature remains neutral with regard to jurisdictional claims in published maps and institutional affiliations.

Ready to submit your research? Choose BMC and benefit from:

- fast, convenient online submission

- thorough peer review by experienced researchers in your field

- rapid publication on acceptance

- support for research data, including large and complex data types

- gold Open Access which fosters wider collaboration and increased citations

- maximum visibility for your research: over $100 \mathrm{M}$ website views per year

At $\mathrm{BMC}$, research is always in progress.

Learn more biomedcentral.com/submissions 